\title{
Paternal childcare in early childhood and problematic behavior in children: a population-based prospective study in Japan
}

Manami Ochi ${ }^{1,2^{*}}$ and Takeo Fujiwara ${ }^{2}$

\begin{abstract}
Background: There have been numerous reports on the effects of paternal childcare on children's behavioral development. However, little is known about these effects in Asian countries such as Japan, where fathers do not have sufficient time for childcare due to long working hours. This study explored the association between paternal childcare during toddlerhood in terms of childcare hours and the type of caregiving behavior and subsequent behavioral problems in children aged 5.5 years, stratified by sex.

Methods: We analyzed data from the Longitudinal Survey of Newborns in the twenty-first Century (2001-2006), a population-based cohort survey in Japan $(N=27,870)$. Paternal childcare was assessed at 18 months in terms of paternal childcare hours on weekdays or weekends and the frequency of each type of childcare (feeding, changing diapers, bathing, putting the child to sleep, playing with the child at home, and taking the child outside). Based on the frequency or lack of paternal involvement, six categories of child behavioral problems were assessed when the children were 5.5 years old. Logistic regression analysis was applied to account for the known confounding variables.

Results: Longer paternal childcare hours, on both weekdays and weekends in toddlerhood, had a protective effect on behavioral problems at 5.5 years of age. The dose-effect relationships were found between the frequency of fathers taking their children outside and behavioral problems in boys, and the frequency of fathers playing with their children at home and behavioral problems in both boys and girls.

Conclusions: Paternal childcare during toddlerhood could prevent subsequent behavioral problems in children. Several specific paternal caregiving behaviors, such as taking their children outside and playing with them at home, may play an important role in preventing subsequent behavioral problems.
\end{abstract}

Keywords: Father, Behavioral problem, Parenting, Early childhood, Longitudinal data

\footnotetext{
* Correspondence: ochi.m.aa@niph.go.jp

${ }^{1}$ Department of Health and Welfare Services, National Institute of Public

Health, 2-3-6 Minami, Wako City, Saitama, Japan

${ }^{2}$ Department of Global Health Promotion, Tokyo Medical and Dental

University, 1-5-45 Yushima, Bunkyo-ku, Tokyo, Japan
}

(c) The Author(s). 2021 Open Access This article is licensed under a Creative Commons Attribution 4.0 International License, which permits use, sharing, adaptation, distribution and reproduction in any medium or format, as long as you give appropriate credit to the original author(s) and the source, provide a link to the Creative Commons licence, and indicate if changes were made. The images or other third party material in this article are included in the article's Creative Commons licence, unless indicated otherwise in a credit line to the material. If material is not included in the article's Creative Commons licence and your intended use is not permitted by statutory regulation or exceeds the permitted use, you will need to obtain permission directly from the copyright holder. To view a copy of this licence, visit http://creativecommons.org/licenses/by/4.0/ The Creative Commons Public Domain Dedication waiver (http://creativecommons.org/publicdomain/zero/1.0/) applies to the data made available in this article, unless otherwise stated in a credit line to the data. 


\section{Background}

An increasing body of research has shown that paternal childcare in early childhood can contribute to child socioemotional development and well-being in various ways [1]. While most studies focus on the importance of mother-baby interaction in childcare, increased involvement in childcare by fathers is associated with multiple aspects of child health and well-being, such as higher cognitive skills $[2,3]$, receptive language skills $[3,4]$, better anthropometric outcomes [5], improved social competence [6], higher educational attainment $[7,8]$, and fewer injuries [9].

Although there is evidence to support the positive impact of fathers' involvement on children's social and behavioral outcomes [10], other evidence on the specific benefits of paternal engagement with children during toddlerhood and its impact on children's behavioral outcome remain limited [11-13]. Direct engagement with children includes caregiving behaviors, such as feeding, changing diapers, playing, and social activities that promote the socio-psychological development of children [1]. Childcare provided by fathers may lead to increased maternal relaxation time and improved maternal mental health and may eventually affect their interactions with their children. Therefore, future research needs to consider not only the duration but also the extent of paternal childcare [14].

Certain types of paternal involvement with children may be partly determined by the child's characteristics. For example, previous studies using path analysis found bidirectional associations between paternal involvement and child behavior, and a tendency for children with conduct problems or hyperactivity to have less involved fathers at subsequent ages $[13,15]$. Children's characteristics are also strongly associated with their developmental behaviors. Paternal childcare is responsive to the child's temperament or disabilities, and children with difficulties may elicit less paternal involvement $[15,16]$; however, few studies have taken this into account.

Further, previous studies on paternal childcare and its effect on child behavior have been limited to Western countries [17]. Parental behavior is highly contextdependent and diverse depending on various societal factors: geographical conditions, family characteristics, economic status, work-related factors, societal norms and beliefs, and so on $[18,19]$. In Japan, where working and commuting hours are longer than in Western countries, many fathers are unable to spend a satisfactory amount of time with their children [20], and the impact of paternal engagement in childcare on children remains unclear.

This study aims to clarify the impact of paternal childcare during toddlerhood on behavioral problems among preschoolers in Japan, in terms of 1) childcare hours and 2 ) the type of caregiving in the Japanese population.

\section{Methods}

\section{Study sample}

We used data from the Longitudinal Survey of Newborns in the twenty-first Century, a populationbased survey conducted by the Ministry of Health, Labor, and Welfare in Japan. The study sample included all babies born in Japan between January 10 and 17 or July 10 and 17, 2001, using birth records from national vital statistics. The baseline survey was mailed to parents when their infants were 6 months old $(n=53,575)$. After the baseline survey, annual surveys were conducted by sending questionnaires to participants by mail. We used data from 2001, 2002, and 2006 survey waves. We included children who lived with both parents and children whose mothers answered the questionnaire to maintain consistency in the assessment of childcare. We excluded responses with missing data for the variables used in the analysis: child problem behavior, paternal involvement in childcare and domestic chores, maternal involvement in childcare and domestic chores, parental education, parental employment, annual household income in 2002, gestational age, weight at birth, and child temperament.

\section{Exposure: paternal childcare}

Paternal childcare was assessed at 18 months of age using the following two measurements: paternal childcare hours on weekdays or weekends, and frequency of each type of caregiving (feeding, changing diapers, bathing, putting the child to sleep, playing with the child at home, and taking the child outside).

Paternal childcare hours were ascertained by asking the following questions: How much time does the father spend with his child on average in 1 day, except for sleeping hours? Respondents answered in respect of both weekdays and weekends by choosing from the following options: none, $<0.5 \mathrm{~h}, 0.5-0.9 \mathrm{~h}, 1-1.9 \mathrm{~h}, 2-3.9 \mathrm{~h}, 4-5.9$ $\mathrm{h}$, and $\geq 6 \mathrm{~h}$. In general, working fathers are expected to spend more time in childcare on weekends than on weekdays; therefore, we re-defined the categories into "less than 0.5 hours," " 0.5 to 1.9 hours," and " 2 or more hours" for weekdays, and "less than 4 hours," "4 to 5.9 hours," and " 6 or more hours" for weekends.

The frequency of each type of paternal caregiving was retrieved using six items: 1) feeding, 2) changing diapers, 3 ) bathing, 4) putting the child to sleep, 5) playing with the child at home, and 6) taking the child outside. Responses for each question included "not at all," "rarely," "sometimes," and "always" For these categories, we classified "always" and "sometimes" as a high degree of paternal caregiving, and "rarely" and "not at all" as a low degree of paternal caregiving. To calculate the total paternal caregiving scores, each response was scored from 0 to 3 (i.e., "not at all" $=0$ and "always" $=3$ ). The 
measurement and the method of specifying the caregiving variable were in line with previous studies $[9,21]$. We divided the total caregiving scores into three groups, namely the "high degree of paternal caregiving" group with more than 1 SD above the mean, the "low degree of paternal caregiving" group with less than 1 SD under the mean, and the "middle degree of paternal caregiving" group.

\section{Outcome: child behavioral problems}

Child behavioral problems were assessed when the children were 5.5 years old by asking the following six questions that required a yes/no response: 1) Is your child able to listen without fidgeting? 2) Is your child able to focus on a specific task? 3) Is your child patient? 4) Is your child able to express their emotions appropriately? 5) Is your child able to behave in a group situation? 6) Is your child able to keep promises? These variables were developed to identify early signs of behavioral and developmental problems and have been previously used as a set of measurements for behavioral problems [22, 23]. In addition, we defined children with any of these problem behaviors as "children with behavioral problems."

\section{Covariates}

We selected the following variables as potential confounders: the number of siblings, living with grandparent(s), paternal and maternal age at childbirth $(<25$ years, 25-29 years, 30-34 years, 35-39 years, and $\geq 40$ years), paternal and maternal education (lower than high school degree, high school degree, 2-year college or vocational school degree, and a college degree or more), annual household income in 2002 (< JPY 4 million, 45.9 million, 6-7.9 million, 8-9.9 million, and $\geq 10$ million), maternal childcare hours on weekdays or weekends at 18 months old, and total scores of maternal involvement in caregiving. Maternal involvement in caregiving was scored using the same items used to assess fathers' involvement in caregiving, and the summed score of the six items was used in the analysis.

How fathers are involved with their children is affected by factors relating to the children themselves, such as disabilities and temperament [24-26]. Therefore, the baseline characteristics of children should also be considered when estimating the effect of paternal childcare: gestational age ( $<37$ weeks, $37-41$ weeks, and $\geq 42$ weeks), multiple birth (singleton, twins, and triplets), child's history of hospital admission or visits for congenital diseases, and child's temperament (self-reported dichotomous answers to questions about 18 traits: active, shy of strangers, playful, short-tempered, careful, aggressive, timid, competitive, obedient, independent, stubborn, full of curiosity, fickle, restless, shy, spoilt, easygoing, and impatient).

\section{Statistical analysis}

We developed logistic regression models for child behavioral problems as predicted by the paternal childcare duration and caregiving score adjusting for covariates shown above. In addition to the crude models, two adjusted models were used: Model 1 adjusted for all covariates shown above, and Model 2 additionally adjusted for other variables of paternal childcare to examine how each of the paternal childcare variables, that is, paternal childcare hours on weekdays, weekends, and total caregiving scores, affected a child's behavioral problems. We also examined whether the frequency of each type of paternal caregiving was associated with each type of child behavioral problem after adjusting for paternal childcare hours. Finally, to ascertain any evidence of interaction between the main exposure variables and the child's sex, we conducted a supplementary analysis in which those interaction terms were added into the model.

All analyses were conducted separately for boys and girls because the effects of paternal childcare may differ due to biologically established sex differences in child development [27]. Analyses were performed using Stata version 15.0 (Stata Corp., College Station, TX, USA).

Approval from the ethics committee of the Tokyo Medical and Dental University was waived because the data were anonymous and available from the Ministry of Health, Labour, and Welfare in Japan upon request. Questionnaire responses from caregivers were considered as informed consent to participate in the study.

\section{Results}

A total of 47,015 caregivers responded to the baseline questionnaire in 2001 (response rate: 87.7\%), 43,925 (93.4\%) caregivers responded in the 2002 survey wave, and 38,540 (82.0\%) responded in the 2006 survey wave. We excluded the children who did not live with both parents or whose mothers did not answer the questionnaire $(n=3458,9.0 \%)$. We excluded responses that did not comprise the following values: child problem behavior $(n=1443,3.7 \%)$, paternal involvement in childcare and domestic chores $(n=2533,6.6 \%)$, maternal involvement in childcare and domestic chores $(n=1277,3.3 \%)$, parental education $(n=578,1.5 \%)$, parental employment ( $n=807,2.1 \%)$, annual household income in $2002(n=$ $2705,7.0 \%)$, gestational age $(n=14,0.04 \%)$, weight at birth $(n=7,0.02 \%)$, and child temperament $(n=374$, $1.0 \%)$. Finally, 27,870 newborns were included in the analyses $(72.3 \%$ of the respondents in the 2006 survey wave). Paternal caregiving in one type of activity was not strongly correlated with that in another type of activity (Spearman's correlation coefficients ranging from 0.270.50 , Table 1). The total paternal caregiving scores ranged from 0 to 18 (Cronbach's alpha $=0.77$ ). 
Table 1 Spearman correlation coefficients between specific types of paternal involvement in caregiving

\begin{tabular}{lllllll}
\hline & 1) & 2) & 3) & 4) & 5) & 6) \\
\hline 1) Feeding & 1.00 & & & & & \\
2) Changing diaper & 0.50 & 1.00 & & & & \\
3) Bathing & 0.35 & 0.31 & 1.00 & & & \\
4) Putting the child to sleep & 0.42 & 0.42 & 0.40 & 1.00 & & \\
5) Playing with the child at home & 0.35 & 0.31 & 0.36 & 0.30 & 1.00 & \\
6) Taking the child outside & 0.32 & 0.30 & 0.27 & 0.28 & 0.44 & 1.00 \\
\hline
\end{tabular}

Table 2 shows the characteristics of the respondents in total and stratified by child sex. Preterm births and low birth weights accounted for 4.6 and $8.1 \%$, respectively. The mean age of the father and mother at the time of birth was $31.7(\mathrm{SD}=5.3)$ and $29.7(\mathrm{SD}=4.2)$ years, respectively. Half of the families had older siblings when the participating child was born. One of the five families lived with grandparents. The percentage of the history of hospital visits or admissions due to a child's congenital diseases was 2.2 and 1.0\%, respectively. Large differences in proportion were shown between boys and girls in some of the children's temperament traits (e.g., $42.8 \%$ for playful boys compared to $31.1 \%$ for playful girls).

The distribution of paternal childcare hours and the frequency of each type of caregiving are shown in Table 3. On weekdays, $47.9 \%$ of the fathers spent two or more hours with their children. On weekends, $70.1 \%$ of the fathers spent six or more hours with their children. Little difference was found in these proportions between boys and girls. The total score of paternal caregiving was distributed normally, with a mean of 11.1 and a standard error of 0.02. For half of the types of caregiving (i.e., bathing, putting the child to sleep, and taking the child outside), the proportion of fathers who were involved in caregiving "sometimes" or "always," was higher in case of boys than girls.

Table 4 shows the mean of the number of behavioral problems and the percentage of each behavioral problem by sex. Being unable to focus on a specific task was the most observed behavioral problem: $23.9 \%$ of the children. Being unable to express emotions appropriately was the second highest (22.9\%), followed by being unable to keep promises (18.9\%) and being unable to listen without fidgeting (17\%). Boys were more likely to have behavioral problems than girls (1.2 vs. 0.8) and had a significantly higher proportion of behavioral problems than girls, except for "being unable to focus on a specific task."

Table 5 shows the results of the logistic regression analysis to estimate how paternal childcare contributed to behavioral problems in boys and girls. In Model 1, adjusting for covariates, children whose fathers spent two or more hours on weekdays with them had a smaller number of behavioral problems (for boys: OR: 0.70, 95\% CI: 0.60 to 0.82 ; for girls: OR: $0.81,95 \% \mathrm{CI}: 0.70$ to 0.95 ) as compared with children whose fathers spent less than half an hour on weekdays with them. In addition, children whose fathers spent six or more hours with them on weekends had fewer behavioral problems (for boys: OR: $0.81,95 \%$ CI: 0.73 to 0.90 ; for girls: OR: 0.85 , $95 \%$ CI: 0.76 to 0.94 ) than children whose fathers spent less than $4 \mathrm{~h}$ with them on weekends. Children who received a high degree of paternal caregiving, defined as more than $1 \mathrm{SD}$ above the mean of the total paternal caregiving score (i.e., 14.3 points), were observed to have a smaller number of behavioral problems (for boys: OR: 0.76, 95\% CI: 0.67 to 0.88 ; for girls: OR: $0.77,95 \% \mathrm{CI}$ : 0.67 to 0.89 ) as compared with children who received a low degree of paternal caregiving. When paternal childcare hours and paternal caregiving scores were adjusted simultaneously in Model 2, the association between paternal childcare hours and problem behaviors remained in boys (for weekdays: OR: 0.71, 95\% CI: 0.60 to 0.84 ; for weekends: $0.86,95 \%$ CI: 0.76 to 0.96 in Table 5), but there was no significant association between total caregiving score and problem behaviors in boys. For girls, the association between paternal childcare hours on weekdays and problem behaviors remained (OR: 0.83, 95\% CI: 0.71 to 0.99 ). Paternal childcare hours on weekends were protective against problem behaviors in girls, although the difference was not statistically significant (OR: 0.89 , 95\% CI: 0.79 to 1.00 ). There was no significant multicollinearity among the variables adjusted for in Model 2. The coefficients of covariates adjusted in Models 1 and 2 of Table 5 are shown in the Additional Tables 1, 2, 3, and 4 .

Several paternal caregiving behaviors decreased specific problem behaviors in children, as shown in Tables 6 and 7. For example, boys whose fathers always fed them had fewer behavioral problems, such as not listening without fidgeting (OR: $0.74,95 \% \mathrm{CI}: 0.61$ to 0.90 ), not being patient (OR: 0.76, 95\% CI: 0.63 to 0.90 ), and not keeping promises (OR: 0.82, 95\% CI: 0.68 to 0.99 , Table 6). In addition, boys whose fathers always changed their diapers had fewer behavioral problems such as not listening without fidgeting (OR: $0.73,95 \% \mathrm{CI}: 0.60$ to 0.90), not focusing on a specific task (OR: 0.74, 95\% CI: 0.58 to 0.95$)$, and not expressing their emotions appropriately (OR: $0.80,95 \%$ CI: 0.66 to 0.97 ). Paternal childcare, such as playing with their children at home or taking their children outside, had a protective doseeffect on most behavioral problems in boys at age 5.5 (all p for trend $<0.05$, except for expressing emotions appropriately).

Girls whose fathers always fed them or changed their diapers had fewer problems with patience (OR: 0.74, 95\% CI: 0.60 to 0.92 ) (Table 7). Fathers playing at home 
Table 2 Characteristics of the participants

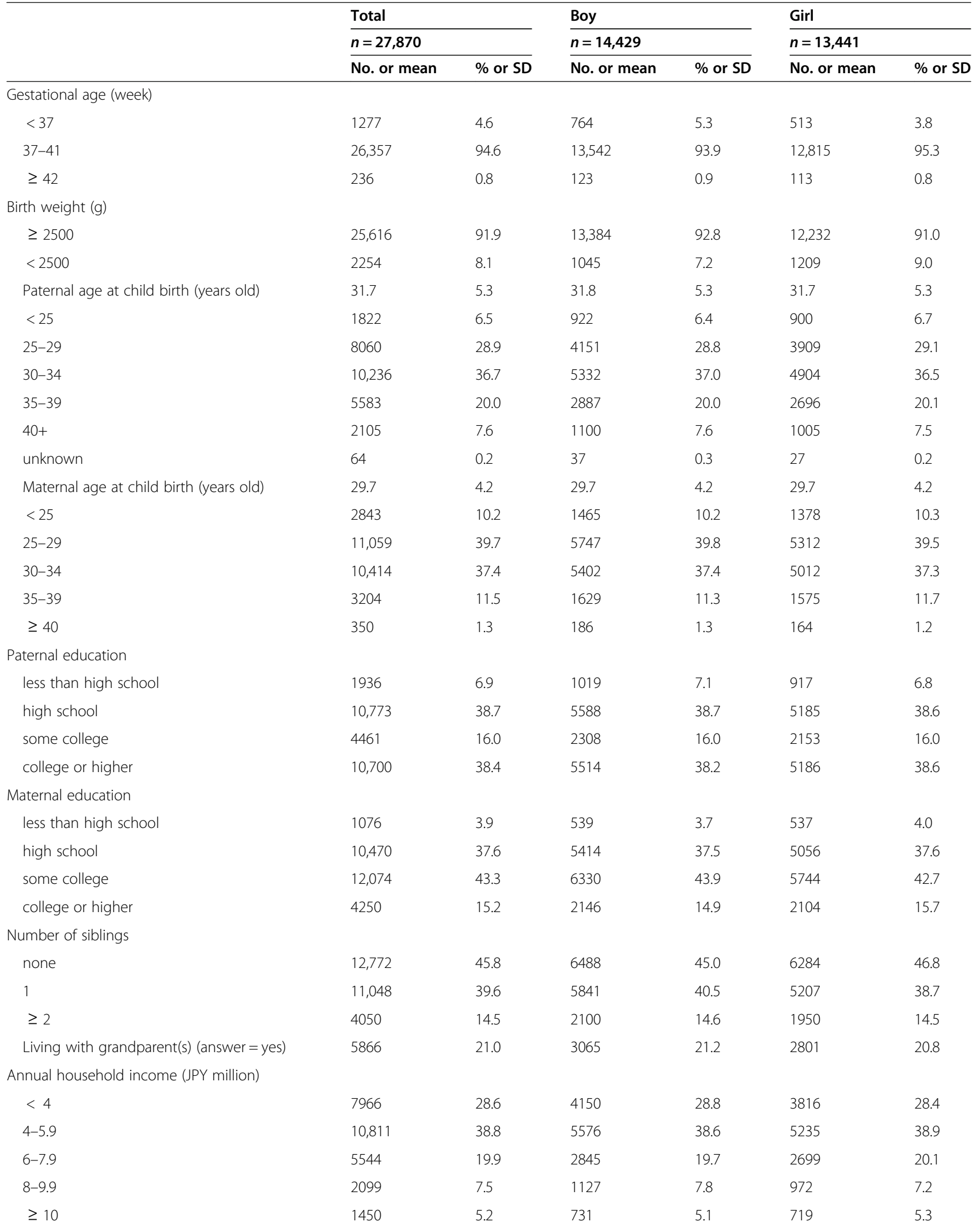


Table 2 Characteristics of the participants (Continued)

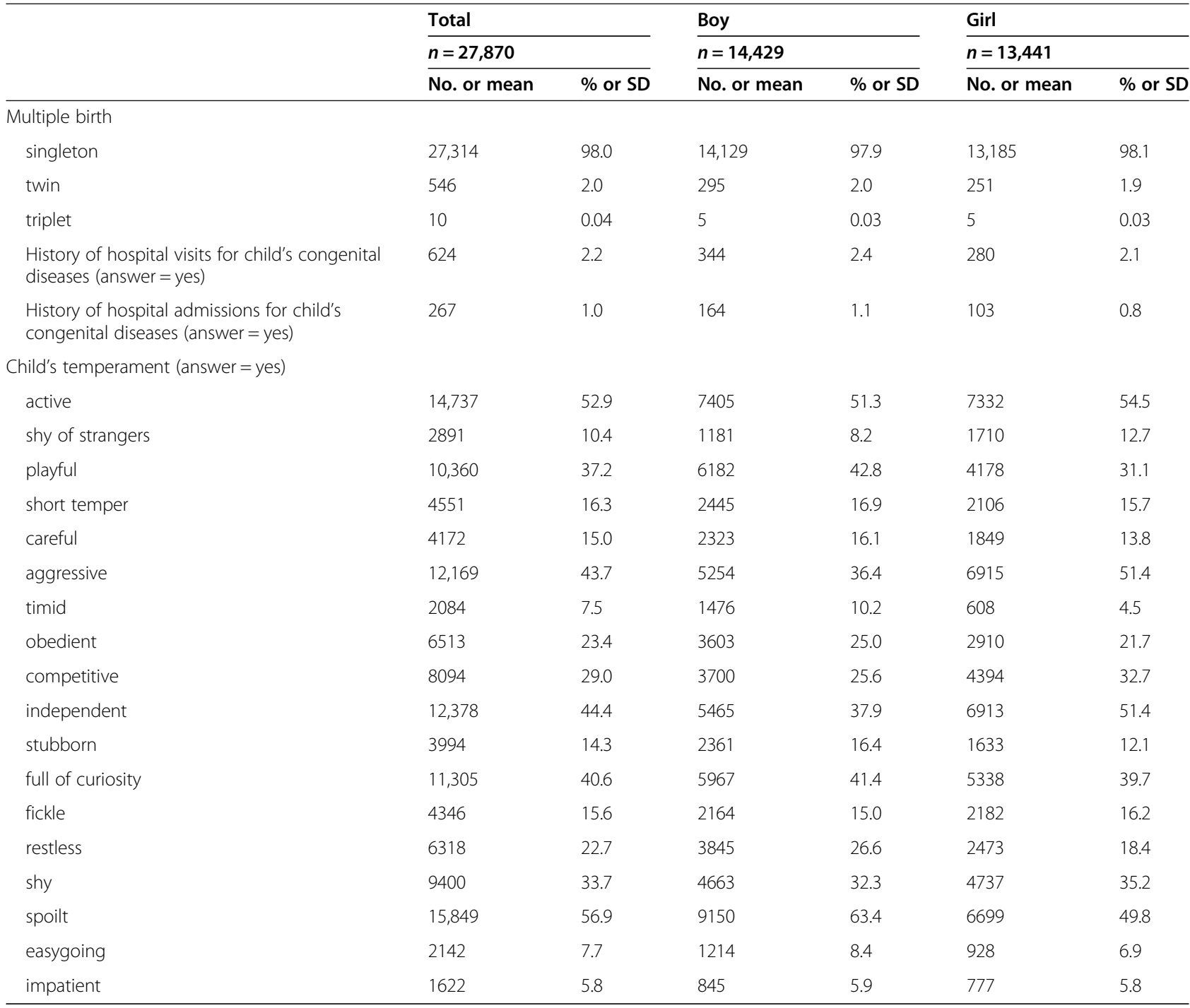

SD Standard deviation

with their children had a protective dose-effect on all types of problem behaviors in girls at age 5 (all $\mathrm{p}$ for trend <0.05). Interestingly, girls whose fathers sometimes put them to sleep had more problematic behaviors, such as always fidgeting while listening (OR: 1.20, 95\% CI: 1.03 to 1.40) and not expressing their emotions appropriately (OR: 1.14, 95\% CI: 1.01 to 1.29 ) than girls whose fathers never put them to sleep.

Additional Tables 5 and 6 show the results of adding to the model the interaction terms between each main exposure and sex. Most results confirm the main effect that girls have less problematic behavior than boys, although the effects of interaction were not clear.

\section{Discussion}

The present study examined the association between paternal childcare during toddlerhood and behavioral problems at 5.5 years of age using a Japanese nationwide population-based longitudinal cohort. Our findings suggest that longer paternal childcare hours in the toddler period were associated with a lower risk of behavioral problems at 5.5 years of age, even after adjusting for paternal parenting behaviors in toddlerhood. We also found that several paternal caregiving behaviors showed a strong preventive effect on specific problem behaviors in children, such as taking the child outside for boys and playing at home for both boys and girls.

The protective effect of paternal involvement in childcare on children's subsequent behavioral problems is consistent with previous studies that reported that child appropriate behavior was positively associated with parenting by the father, after adjusting for other confounders, including parenting by the mother $[10,12,28$, 29]. The current study also revealed the effect of 
Table 3 The distributions of paternal childcare

\begin{tabular}{|c|c|c|c|c|c|c|c|}
\hline & \multicolumn{2}{|l|}{$\begin{array}{l}\text { Total } \\
n=27,870\end{array}$} & \multicolumn{2}{|l|}{$\begin{array}{l}\text { Boy } \\
n=14,429\end{array}$} & \multicolumn{2}{|l|}{$\begin{array}{l}\text { Girl } \\
n=13,441\end{array}$} & \multirow[t]{2}{*}{$p$ value $^{*}$} \\
\hline & No. or mean & $\%$ or $\mathrm{SE}$ & No. or mean & $\%$ or $\mathrm{SE}$ & No. or mean & $\%$ or $\mathrm{SE}$ & \\
\hline \multicolumn{8}{|l|}{ Childcare hour on weekdays (hour) } \\
\hline$<0.5$ & 4747 & 17.0 & 2456 & 17 & 2291 & 17.0 & 0.89 \\
\hline $0.5-0.9$ & 3654 & 13.1 & 1905 & 13.2 & 1749 & 13.0 & \\
\hline $1-1.9$ & 6104 & 21.9 & 3141 & 21.8 & 2963 & 22.0 & \\
\hline $2-3.9$ & 9432 & 33.8 & 4864 & 33.7 & 4568 & 34.0 & \\
\hline $4-5.9$ & 3348 & 12.0 & 1749 & 12.1 & 1599 & 11.9 & \\
\hline$\geq 6$ & 585 & 2.1 & 314 & 2.2 & 271 & 2.0 & \\
\hline \multicolumn{8}{|l|}{ Childcare hour on weekends (hour) } \\
\hline$<0.5$ & 299 & 1.1 & 158 & 1.1 & 141 & 1.0 & 0.77 \\
\hline $0.5-0.9$ & 470 & 1.7 & 243 & 1.7 & 227 & 1.7 & \\
\hline $1-1.9$ & 1027 & 3.7 & 521 & 3.6 & 506 & 3.8 & \\
\hline $2-3.9$ & 2521 & 9.0 & 1326 & 9.2 & 1195 & 8.9 & \\
\hline $4-5.9$ & 4014 & 14.4 & 2044 & 14.2 & 1970 & 14.7 & \\
\hline$\geq 6$ & 19,539 & 70.1 & 10,137 & 70.3 & 9402 & 70.0 & \\
\hline Total caregiving score (range: 0 to 18 ) & 11.1 & 0.02 & 11.2 & 0.03 & 11.0 & 0.03 & $<0.001$ \\
\hline \multicolumn{8}{|l|}{ Frequency of feeding } \\
\hline not at all & 3336 & 12.0 & 1733 & 12.0 & 1603 & 11.9 & 0.28 \\
\hline rarely & 7346 & 26.4 & 3738 & 25.9 & 3608 & 26.8 & \\
\hline sometimes & 14,593 & 52.4 & 7586 & 52.6 & 7007 & 52.1 & \\
\hline always & 2595 & 9.3 & 1372 & 9.5 & 1223 & 9.1 & \\
\hline \multicolumn{8}{|l|}{ Frequency of changing diaper } \\
\hline not at all & 3416 & 12.3 & 1763 & 12.2 & 1653 & 12.3 & 0.72 \\
\hline rarely & 6571 & 23.6 & 3396 & 23.5 & 3175 & 23.6 & \\
\hline sometimes & 15,631 & 56.1 & 8078 & 56.0 & 7553 & 56.2 & \\
\hline always & 2252 & 8.1 & 1192 & 8.3 & 1060 & 7.9 & \\
\hline \multicolumn{8}{|l|}{ Frequency of bathing } \\
\hline not at all & 1337 & 4.8 & 612 & 4.2 & 725 & 5.4 & $<0.001$ \\
\hline rarely & 2612 & 9.4 & 1291 & 8.9 & 1321 & 9.8 & \\
\hline sometimes & 13,954 & 50.1 & 7181 & 49.8 & 6773 & 50.4 & \\
\hline always & 9967 & 35.8 & 5345 & 37.0 & 4622 & 34.4 & \\
\hline \multicolumn{8}{|l|}{ Frequency of putting the child to sleep } \\
\hline not at all & 5601 & 20.1 & 2703 & 18.7 & 2898 & 21.6 & $<0.001$ \\
\hline rarely & 8268 & 29.7 & 4218 & 29.2 & 4050 & 30.1 & \\
\hline sometimes & 10,950 & 39.3 & 5803 & 40.2 & 5147 & 38.3 & \\
\hline always & 3051 & 10.9 & 1705 & 11.8 & 1346 & 10.0 & \\
\hline \multicolumn{8}{|l|}{ Frequency of playing with the child at home } \\
\hline not at all & 165 & 0.6 & 82 & 0.6 & 83 & 0.6 & 0.61 \\
\hline rarely & 1126 & 4.0 & 582 & 4.0 & 544 & 4.0 & \\
\hline sometimes & 13,846 & 49.7 & 7120 & 49.3 & 6726 & 50.0 & \\
\hline always & 12,733 & 45.7 & 6645 & 46.1 & 6088 & 45.3 & \\
\hline
\end{tabular}


Table 3 The distributions of paternal childcare (Continued)

\begin{tabular}{|c|c|c|c|c|c|c|c|}
\hline & \multicolumn{2}{|l|}{$\begin{array}{l}\text { Total } \\
n=27,870\end{array}$} & \multicolumn{2}{|l|}{$\begin{array}{l}\text { Boy } \\
n=14,429\end{array}$} & \multicolumn{2}{|l|}{$\begin{array}{l}\text { Girl } \\
n=13,441\end{array}$} & \multirow[t]{2}{*}{$p$ value* } \\
\hline & No. or mean & $\%$ or SE & No. or mean & $\%$ or SE & No. or mean & $\%$ or SE & \\
\hline \multicolumn{8}{|c|}{ Frequency of taking the child outside } \\
\hline not at all & 917 & 3.3 & 457 & 3.2 & 460 & 3.4 & \multirow[t]{4}{*}{$<0.001$} \\
\hline rarely & 3717 & 13.3 & 1826 & 12.7 & 1891 & 14.1 & \\
\hline sometimes & 18,882 & 67.8 & 9805 & 68.0 & 9077 & 67.5 & \\
\hline always & 4354 & 15.6 & 2341 & 16.2 & 2013 & 15.0 & \\
\hline
\end{tabular}

SE Standard error, ${ }^{*}$ Chi-square test

paternal time spent with children on respective weekdays and weekends on preschooler's behavior. Previous studies have suggested that paternal behavior is likely to be influenced by the characteristics of employment and workplace [30, 31]. Therefore, these studies noted the importance of separately considering the fathers' weekday and weekend involvement with their children. However, research thus far has not examined the extent to which childcare on weekdays and weekends predict child behavioral outcomes. The results have important policy implications for populations in Japan, where fathers work long hours, even when their children are infants/ toddlers, and thus do not have sufficient time for childcare. On the other hand, the overall frequency of paternal childcare during toddlerhood was not independently associated with behavioral problems in children at 5.5 years of age, after adjusting for the amount of time fathers spent with their children, suggesting that the duration matters for children's subsequent behavioral problems. Previous studies have reported that fathers' parenting quality, as well as the quantity of routine care provided, are associated with a lower risk of child behavioral problems $[12,28]$. In addition, fathers who spend more time on child caregiving have a higher quality of interaction with their children, because primary caregiving fathers have a better understanding of how to care for and play with their children as a result of the greater time they have spent with them [32]. This study did not directly measure the quality of parenting; however, spending more time with children on weekdays and weekends could improve paternal caregiving skills, which may have a positive impact on children's behavior.

Previous studies have consistently reported that mothers typically spend a significant number of hours caring for their children, whereas fathers spend a greater number of hours playing with their children. Our findings highlight that the impact of fathers' involvement on their children's behavior can differ depending on what type of parenting fathers engage in, such as essential routine cares or play with the child. Children whose fathers were always involved in some type of essential childcare, such as feeding and changing diapers, had fewer problems in specific behaviors. Possibly, paternal childcare, which is essential for a child's life, might help reduce the mothers' childcare burdens and contribute to lower maternal stress, which is considered as a risk for behavioral problems in children [33, 34]. On the other hand, playing with children at home or taking them outside is a more complex type of interaction between fathers and children, which is an important stimulus for the child's socioemotional development [35]. Therefore, in this study, we found that these types of paternal

Table 4 The number of children with behavioral problems

\begin{tabular}{|c|c|c|c|c|c|c|c|}
\hline & \multicolumn{2}{|l|}{$\begin{array}{l}\text { Total } \\
n=27,870\end{array}$} & \multicolumn{2}{|l|}{$\begin{array}{l}\text { Boy } \\
n=14,429\end{array}$} & \multicolumn{2}{|l|}{$\begin{array}{l}\text { Girl } \\
n=13,441\end{array}$} & \multirow[t]{2}{*}{$p$ value $^{*}$} \\
\hline & mean or No. & SE or $\%$ & mean or No. & SE or $\%$ & mean or No. & SE or $\%$ & \\
\hline Number of behavioral problem & 1.0 & 0.01 & 1.2 & 0.01 & 0.8 & 0.01 & $<0.001$ \\
\hline Any of behavioral problems & 13,995 & 50.2 & 7980 & 55.3 & 6015 & 44.8 & $<0.001$ \\
\hline Unable to listen without fidgeting & 4751 & 17.0 & 3131 & 21.7 & 1620 & 12.1 & $<0.001$ \\
\hline Unable to focus on a specific task & 3463 & 12.4 & 1833 & 12.7 & 1630 & 12.1 & 0.15 \\
\hline Unable to be patient & 6656 & 23.9 & 3930 & 27.2 & 2726 & 20.3 & $<0.001$ \\
\hline Unable to express emotions appropriately & 6375 & 22.9 & 3672 & 25.4 & 2703 & 20.1 & $<0.001$ \\
\hline Unable to behave in a group situation & 1656 & 5.9 & 1086 & 7.5 & 570 & 4.2 & $<0.001$ \\
\hline Unable to keep promises & 5270 & 18.9 & 3117 & 21.6 & 2153 & 16.0 & $<0.001$ \\
\hline
\end{tabular}

SE Standard error, * t-test or Chi-square test 
Table 5 The effects of paternal childcare-hour and caregiving score on behavioral problems in 5.5 year-old children; result of the logistic regression model

\begin{tabular}{|c|c|c|c|c|c|c|c|c|c|}
\hline & \multicolumn{3}{|c|}{ Crude model } & \multicolumn{3}{|c|}{ Model 1} & \multicolumn{3}{|c|}{ Model 2} \\
\hline & \multirow[t]{2}{*}{$\overline{O R}$} & \multicolumn{2}{|l|}{$95 \% \mathrm{Cl}$} & \multirow[t]{2}{*}{$\overline{\text { OR }}$} & \multicolumn{2}{|l|}{$95 \% \mathrm{Cl}$} & \multirow[t]{2}{*}{$\overline{O R}$} & \multicolumn{2}{|c|}{$95 \% \mathrm{Cl}$} \\
\hline \multicolumn{7}{|l|}{ Boys } & & & \\
\hline \multicolumn{10}{|c|}{ Childcare-hour on weekdays (ref. $<0.5$ h) } \\
\hline 0.5 to $1.9 \mathrm{~h}$ & 0.91 & 0.78 & 1.05 & 0.82 & 0.70 & 0.96 & 0.82 & 0.70 & 0.96 \\
\hline \multirow[t]{2}{*}{$\geq 2 \mathrm{~h}$} & 0.87 & 0.75 & 1.01 & 0.70 & 0.60 & 0.82 & 0.71 & 0.60 & 0.84 \\
\hline & \multicolumn{3}{|c|}{ ( $p$ for trend) 0.07} & \multicolumn{3}{|c|}{$(p$ for trend $)<0.001$} & \multicolumn{3}{|c|}{ ( $p$ for trend) $<0.001$} \\
\hline \multicolumn{10}{|c|}{ Childcare-hour on weekends (ref. $<4 \mathrm{~h}$ ) } \\
\hline 4 to $5.9 \mathrm{~h}$ & 0.93 & 0.82 & 1.05 & 0.92 & 0.81 & 1.05 & 0.96 & 0.84 & 1.10 \\
\hline \multirow[t]{2}{*}{$\geq 6 \mathrm{~h}$} & 0.79 & 0.72 & 0.87 & 0.81 & 0.73 & 0.90 & 0.86 & 0.76 & 0.96 \\
\hline & \multicolumn{3}{|c|}{ ( $p$ for trend) $<0.001$} & \multicolumn{3}{|c|}{$(p$ for trend $)<0.001$} & \multicolumn{3}{|c|}{ ( $p$ for trend) 0.004} \\
\hline \multicolumn{10}{|c|}{ Total caregiving score (ref. low) } \\
\hline middle & 0.92 & 0.83 & 1.02 & 0.87 & 0.78 & 0.97 & 0.98 & 0.87 & 1.10 \\
\hline \multirow[t]{2}{*}{ high } & 0.86 & 0.76 & 0.98 & 0.76 & 0.67 & 0.88 & 0.92 & 0.79 & 1.07 \\
\hline & \multicolumn{3}{|c|}{ ( $p$ for trend) 0.03} & \multicolumn{3}{|c|}{$(p$ for trend $)<0.001$} & \multicolumn{3}{|c|}{ ( $p$ for trend) 0.29} \\
\hline \multicolumn{10}{|l|}{ Girls } \\
\hline \multicolumn{10}{|c|}{ Childcare-hour on weekdays (ref. $<0.5$ h) } \\
\hline 0.5 to $1.9 \mathrm{~h}$ & 0.94 & 0.81 & 1.09 & 0.90 & 0.77 & 1.05 & 0.91 & 0.78 & 1.06 \\
\hline \multirow[t]{2}{*}{$\geq 2 \mathrm{~h}$} & 0.95 & 0.82 & 1.11 & 0.81 & 0.70 & 0.95 & 0.83 & 0.71 & 0.99 \\
\hline & \multicolumn{3}{|c|}{ ( $p$ for trend) } & \multicolumn{3}{|c|}{ ( $p$ for trend) 0.001} & ( $p$ for & 0.02 & \\
\hline Childcare-hour & ekends & $4 \mathrm{~h})$ & & & & & & & \\
\hline 4 to $5.9 \mathrm{~h}$ & 0.99 & 0.88 & 1.12 & 1.00 & 0.88 & 1.14 & 1.05 & 0.91 & 1.20 \\
\hline$\geq 6 \mathrm{~h}$ & 0.79 & 0.72 & 0.87 & 0.85 & 0.76 & 0.94 & 0.89 & 0.79 & 1.00 \\
\hline & ( $p$ for & $<0.001$ & & ( $p$ for & 0.001 & & ( $p$ for & 0.01 & \\
\hline Total caregivin & (ref. lo & & & & & & & & \\
\hline middle & 0.91 & 0.82 & 1.00 & 0.85 & 0.76 & 0.94 & 0.91 & 0.81 & 1.01 \\
\hline high & 0.90 & 0.78 & 1.02 & 0.77 & 0.67 & 0.89 & 0.88 & 0.75 & 1.03 \\
\hline & ( $p$ for & 0.10 & & ( $p$ for & 0.001 & & ( $p$ for & 0.11 & \\
\hline
\end{tabular}

${ }^{a}$ Model 1 adjusted covariates variables (number of siblings, living with grandparent(s), paternal and maternal age at child birth, paternal and maternal education, annual household income, maternal childcare-hours on weekdays or weekends at 18 months old, and the total scores of maternal involvement in caregiving, multiple birth, gestational age, child's history of hospital admission or visits for congenital diseases, child's temperament).

${ }^{\mathrm{b}}$ Model 2 adjusted for Model 1 and other veriables of paternal childcare.

'Bold values denote statistical significance at the $p<0.05$

$O R$ Odds ratio; $\mathrm{Cl}$ Confidence interval

caregiving could have preventive effects on a variety of problem behaviors in children.

We estimated the sex-specific effects of paternal childcare on behavioral problems in children. Our results did not confirm the sex difference in paternal time spent with the child on weekdays and weekends. Fathers of boys, however, were involved slightly more frequently than those of girls in several types of caregiving, such as bathing, putting their children to sleep, and taking them outside. These sex differences in paternal involvement have been found in previous studies and are considered to be induced in response to underlying biological or psychosocial differences in children [27, 36]. Moreover, the influence of paternal caregiving on the child's behavior differed depending on the child's sex in this study. For example, boys showed reduced behavioral problems when their fathers often took them outside, while girls showed reduced behavioral problems when their fathers often played with them at home. The reason for these sex-specific effects might be explained by the well-established gender differences in behavior [3638]; however, further research is required.

This study has several strengths. First, in our analysis, we considered the child's original temperament and congenital disabilities, which could be related to the involvement of fathers in parenting as well as behavioral problems in their children. Therefore, the present study provides robust evidence that paternal childcare has a 
Table 6 The effects of paternal childcare on behavioral problems in 5.5 year-old boys; result of the logistic regression model

\begin{tabular}{|c|c|c|c|c|c|c|c|c|c|c|c|c|c|c|c|c|c|c|c|c|}
\hline & \multicolumn{3}{|c|}{$\begin{array}{l}\text { Behavioral } \\
\text { problem }\end{array}$} & \multicolumn{2}{|c|}{$\begin{array}{l}\text { Unable to listen } \\
\text { without } \\
\text { fidgeting }\end{array}$} & \multicolumn{3}{|c|}{$\begin{array}{l}\text { Unable to focus } \\
\text { on a specific } \\
\text { task }\end{array}$} & \multicolumn{3}{|c|}{$\begin{array}{l}\text { Unable to be } \\
\text { patient }\end{array}$} & \multicolumn{3}{|c|}{$\begin{array}{l}\text { Unable to } \\
\text { express } \\
\text { emotions } \\
\text { appropriately }\end{array}$} & \multicolumn{3}{|c|}{$\begin{array}{l}\text { Unable to } \\
\text { behave in a } \\
\text { group situation }\end{array}$} & \multicolumn{3}{|c|}{$\begin{array}{l}\text { Unable to keep } \\
\text { promises }\end{array}$} \\
\hline & $\overline{\mathrm{OR}}$ & $95 \%$ & & $\overline{\mathrm{OR}}$ & $95 \% \mathrm{Cl}$ & $\overline{\text { OR }}$ & 95 & & $\overline{\text { OR }}$ & & & $\overline{\mathrm{OR}}$ & $95 \%$ & & $\overline{\mathrm{OR}}$ & $95 \%$ & & $\overline{\mathrm{OR}}$ & $95 \% \mathrm{C}$ & \\
\hline \multicolumn{21}{|c|}{ Frequency of feeding (ref. not at all) } \\
\hline rarely & 0.85 & 0.76 & 0.97 & 0.80 & $0.70 \quad 0.93$ & 0.99 & 0.83 & 19 & 0.81 & 0.71 & 0.93 & 0.88 & 0.77 & 1.01 & 0.89 & 0.72 & 1.10 & 0.93 & 0.80 & 1.0 \\
\hline sometimes & 0.86 & 0.77 & 0.97 & 0.86 & $0.75 \quad 0.98$ & 1.02 & 0.86 & 1.21 & 0.82 & 0.72 & 0.93 & 0.88 & 0.78 & 1.00 & 0.90 & 0.74 & 1.10 & 0.92 & 0.81 & 1. \\
\hline \multirow[t]{2}{*}{ always } & 0.85 & 0.73 & 0.99 & 0.74 & 0.610 .90 & 0.87 & 0.69 & 1.11 & 0.76 & 0.63 & 0.90 & 0.87 & 0.73 & 1.04 & 0.91 & 0.68 & 1.21 & 0.82 & 0.68 & \\
\hline & \multicolumn{3}{|c|}{ ( $p$ for trend) 0.07} & \multicolumn{2}{|c|}{ ( $p$ for trend) 0.04} & \multicolumn{3}{|c|}{ ( $p$ for trend) 0.55} & \multicolumn{3}{|c|}{ ( $p$ for trend) 0.004} & \multicolumn{3}{|c|}{ ( $p$ for trend) 0.12} & \multicolumn{3}{|c|}{ ( $p$ for trend) 0.51} & \multicolumn{3}{|c|}{ ( $p$ for trend) 0.09} \\
\hline
\end{tabular}

Frequency of changing diaper (ref. not at all)

$\begin{array}{llllllllllllllllllllll}\text { rarely } & 0.90 & 0.80 & 1.02 & \mathbf{0 . 8 4} & \mathbf{0 . 7 2} & \mathbf{0 . 9 7} & 0.87 & 0.73 & 1.04 & 0.90 & 0.79 & 1.03 & 0.97 & 0.85 & 1.11 & 0.99 & 0.79 & 1.24 & 0.96 & 0.83 & 1.11 \\ \text { sometimes } & 0.94 & 0.84 & 1.05 & \mathbf{0 . 8 4} & \mathbf{0 . 7 3} & \mathbf{0 . 9 6} & 0.95 & 0.81 & 1.13 & 0.96 & 0.85 & 1.09 & 0.90 & 0.79 & 1.02 & 1.07 & 0.87 & 1.32 & 1.03 & 0.90 & 1.18 \\ \text { always } & \mathbf{0 . 8 2} & \mathbf{0 . 7 0} & \mathbf{0 . 9 7} & \mathbf{0 . 7 3} & \mathbf{0 . 6 0} & \mathbf{0 . 9 0} & \mathbf{0 . 7 4} & \mathbf{0 . 5 8} & \mathbf{0 . 9 5} & 0.88 & 0.74 & 1.06 & \mathbf{0 . 8 0} & \mathbf{0 . 6 6} & \mathbf{0 . 9 7} & 1.14 & 0.84 & 1.54 & 0.87 & 0.71 & 1.06 \\ & (p \text { for trend) }) & 0.14 & (p \text { for trend) } & \mathbf{0 . 0 1} & (p \text { for trend) } & 0.27 & (p \text { for trend) } & 0.58 & (p \text { for trend) } & \mathbf{0 . 0 1} & (p \text { for trend) } 0.26 & (p \text { for trend) } 0.80\end{array}$

Frequency of bathing (ref. not at all)

$\begin{array}{llllllllllllllllllllll}\text { rarely } & 0.92 & 0.75 & 1.13 & 1.18 & 0.92 & 1.51 & 0.89 & 0.66 & 1.20 & 1.17 & 0.94 & 1.46 & 0.81 & 0.65 & 1.02 & 0.93 & 0.66 & 1.30 & 1.03 & 0.81 & 1.31 \\ \text { sometimes } & 1.00 & 0.83 & 1.19 & 1.09 & 0.88 & 1.35 & 0.96 & 0.74 & 1.24 & 1.01 & 0.83 & 1.23 & 0.88 & 0.73 & 1.07 & 0.80 & 0.59 & 1.08 & 1.10 & 0.89 & 1.37 \\ \text { always } & 0.88 & 0.73 & 1.07 & 1.00 & 0.79 & 1.24 & 0.81 & 0.62 & 1.05 & 0.94 & 0.76 & 1.15 & \mathbf{0 . 7 9} & \mathbf{0 . 6 4} & \mathbf{0 . 9 6} & 0.81 & 0.59 & 1.11 & 1.13 & 0.90 & 1.40 \\ & & (p \text { for trend) } & 0.14 & (p \text { for trend) } & 0.17 & (p \text { for trend) } & 0.06 & (p \text { for trend) } \mathbf{0 . 0 3} & (p \text { for trend) } \mathbf{0 . 0 4} & (p \text { for trend) } 0.16 & (p \text { for trend) } 0.20\end{array}$

Frequency of putting the child to sleep (ref. not at all)

$\begin{array}{llllllllllllllllllllll}\text { rarely } & 0.99 & 0.89 & 1.10 & 1.01 & 0.89 & 1.14 & 0.92 & 0.78 & 1.07 & 0.93 & 0.83 & 1.04 & 0.91 & 0.81 & 1.02 & 0.88 & 0.72 & 1.06 & 1.13 & 1.00 & 1.28 \\ \text { sometimes } & 0.97 & 0.88 & 1.07 & 1.06 & 0.94 & 1.20 & 1.05 & 0.90 & 1.21 & 0.93 & 0.83 & 1.04 & \mathbf{0 . 8 8} & \mathbf{0 . 7 8} & \mathbf{0 . 9 8} & 0.92 & 0.76 & 1.10 & 1.08 & 0.96 & 1.22 \\ \text { always } & 1.04 & 0.91 & 1.19 & 1.06 & 0.90 & 1.25 & 0.89 & 0.72 & 1.09 & 0.90 & 0.77 & 1.04 & 0.94 & 0.80 & 1.09 & 1.14 & 0.90 & 1.45 & 1.20 & 1.02 & 1.41 \\ & & (p \text { for trend) } & 0.93 & (p \text { for trend) } & 0.31 & & (p \text { for trend) } & 0.99 & (p \text { for trend) } 0.20 & (p \text { for trend) } 0.13 & (p \text { for trend) } 0.46 & (p \text { for trend) } 0.11\end{array}$

Frequency of playing with the child at home (ref. not at all)

\begin{tabular}{|c|c|c|c|c|c|c|c|c|c|c|c|c|c|c|c|c|c|c|c|c|c|}
\hline rarely & 1.15 & 0.70 & 1.89 & 1.05 & 0.60 & 1.82 & 0.95 & 0.48 & 1.90 & 0.97 & 0.58 & 1.62 & 0.74 & 0.44 & 1.23 & 0.78 & 0.39 & 1.55 & 0.98 & 0.56 & 1.72 \\
\hline sometimes & 1.06 & 0.66 & 1.70 & 0.73 & 0.43 & 1.23 & 0.81 & 0.42 & 1.57 & 0.86 & 0.53 & 1.40 & 0.77 & 0.48 & 1.25 & 0.55 & 0.29 & 1.06 & 0.90 & 0.53 & .53 \\
\hline \multirow[t]{2}{*}{ always } & 0.95 & 0.59 & 1.51 & 0.64 & 0.38 & 1.10 & 0.75 & 0.38 & 1.45 & 0.79 & 0.48 & 1.30 & 0.65 & 0.40 & 1.05 & 0.50 & 0.26 & 0.98 & 0.82 & 0.48 & 0 \\
\hline & \multicolumn{3}{|c|}{$\begin{array}{l}\text { ( } p \text { for trend) } \\
\mathbf{0 . 0 0 2}\end{array}$} & \multicolumn{3}{|c|}{$\begin{array}{l}(p \text { for trend }) \\
<0.001\end{array}$} & \multicolumn{3}{|c|}{$\begin{array}{l}\text { ( } p \text { for trend) } \\
0.04\end{array}$} & \multicolumn{3}{|c|}{$\begin{array}{l}\text { ( } p \text { for trend) } \\
0.02\end{array}$} & \multicolumn{3}{|c|}{$\begin{array}{l}(p \text { for trend) } \\
<0.001\end{array}$} & \multicolumn{3}{|c|}{$\begin{array}{l}\text { ( } p \text { for trend) } \\
0.01\end{array}$} & \multicolumn{2}{|c|}{$\begin{array}{l}\text { ( } p \text { for trend) } \\
0.02\end{array}$} & \\
\hline
\end{tabular}

Frequency of taking the child outside (ref. not at all)

$\begin{array}{llllllllllllllllllllll}\text { rarely } & 1.05 & 0.84 & 1.31 & 0.85 & 0.66 & 1.09 & 1.03 & 0.76 & 1.41 & 0.91 & 0.72 & 1.15 & 0.90 & 0.71 & 1.15 & 0.88 & 0.62 & 1.25 & 1.01 & 0.79 & 1.29 \\ \text { sometimes } & 0.92 & 0.75 & 1.13 & \mathbf{0 . 7 5} & \mathbf{0 . 6 0} & \mathbf{0 . 9 5} & 0.86 & 0.64 & 1.15 & \mathbf{0 . 8 0} & \mathbf{0 . 6 5} & \mathbf{1 . 0 0} & 0.89 & 0.71 & 1.11 & 0.76 & 0.54 & 1.05 & 0.86 & 0.69 & 1.09 \\ \text { always } & 0.89 & 0.71 & 1.11 & 0.78 & 0.60 & 1.00 & 0.83 & 0.61 & 1.15 & \mathbf{0 . 7 8} & \mathbf{0 . 6 2} & \mathbf{0 . 9 9} & 0.82 & 0.64 & 1.04 & 0.73 & 0.51 & 1.06 & 0.80 & 0.62 & 1.03 \\ & (p \text { for trend) } & \mathbf{0 . 0 2} & (p \text { for trend) } & \mathbf{0 . 0 5} & (p \text { for trend) } & \mathbf{0 . 0 4} & (p \text { for trend) } \mathbf{0 . 0 1} & (p \text { for trend) } 0.08 & (p \text { for trend) } & \mathbf{0 . 0 5} & (p \text { for trend) } \mathbf{0 . 0 0 4}\end{array}$

adjusted covariates (number of siblings, living with grandparent(s), paternal and maternal age at child birth, paternal and maternal education, annual household income, maternal childcare hours on weekdays or weekends at 18 months old, and the total scores of maternal involvement in caregiving, gestational age, multiple birth, child's history of hospital admission or visits for congenital diseases, child's temperament), and parental spending hours with children.

${ }^{\mathrm{b}}$ Bold values denote statistical significance at the $p<0.05$

OR Odds ratio; $\mathrm{Cl}$ Confidence interval

positive effect on children's behavioral problems. Second, these results were obtained from a representative sample in Japan, in which fathers typically spend long hours commuting and working and, therefore, spend less time with their children than fathers in Western countries [39, 40]. This study provided a test of the generalizability of the hypothesis that paternal childcare would have a protective effect on child behavior. Third, we used a prospective cohort study; thus, reverse causation was unlikely.

Despite its strengths, this study also has some limitations. First, we used maternal reports to evaluate paternal childcare because of the lack of precise measures. In addition, our survey did not ask about the actual amount of time spent on each type of paternal caregiving 
Table 7 The effects of paternal childcare on behavioral problems in 5.5 year-old girls; result of the logistic regression model

\begin{tabular}{|c|c|c|c|c|c|c|c|c|c|c|c|c|c|c|c|c|c|c|c|c|c|}
\hline & \multicolumn{3}{|c|}{$\begin{array}{l}\text { Behavioral } \\
\text { problem }\end{array}$} & \multicolumn{3}{|c|}{$\begin{array}{l}\text { Unable to listen } \\
\text { without } \\
\text { fidgeting }\end{array}$} & \multicolumn{3}{|c|}{$\begin{array}{l}\text { Unable to } \\
\text { focus on a } \\
\text { specific task }\end{array}$} & \multicolumn{3}{|c|}{$\begin{array}{l}\text { Unable to be } \\
\text { patient }\end{array}$} & \multicolumn{3}{|c|}{$\begin{array}{l}\text { Unable to } \\
\text { express } \\
\text { emotions } \\
\text { appropriately }\end{array}$} & \multicolumn{3}{|c|}{$\begin{array}{l}\text { Unable to } \\
\text { behave in a } \\
\text { group situation }\end{array}$} & \multicolumn{3}{|c|}{$\begin{array}{l}\text { Unable to keep } \\
\text { promises }\end{array}$} \\
\hline & $\overline{\text { OR }}$ & & & $\overline{O R}$ & & & $\overline{\mathrm{OR}}$ & $95 \%$ & & $\overline{\text { OR }}$ & & & $\overline{\mathrm{OR}}$ & $95 \%$ & & $\mathrm{R}$ & $95 \%$ & & $\overline{O R}$ & & \\
\hline \multicolumn{22}{|c|}{ Frequency of feeding (ref. not at all) } \\
\hline rarely & 1.05 & 92 & 1.18 & 0.96 & 0.79 & 1.16 & 0.95 & 0.79 & 1.15 & 0.96 & 0.82 & 1.11 & 1.02 & 0.88 & 1.18 & 0.87 & 0.65 & 1.15 & 1.15 & 0.97 & 1.3 \\
\hline sometimes & 0.94 & 0.84 & 1.06 & 0.96 & 0.80 & 1.16 & 0.86 & 0.72 & 1.03 & 0.87 & 0.76 & 1.01 & 0.96 & 0.83 & 1.11 & 0.89 & 0.68 & 1.16 & 1.04 & 0.88 & 1.2 \\
\hline \multirow[t]{2}{*}{ always } & 1.01 & 0.85 & 1.19 & 0.85 & 0.66 & 1.10 & 097 & 0.76 & 1.24 & 0.74 & 0.60 & 0.91 & 1.05 & 0.86 & 1.29 & 1.10 & 0.75 & 1.61 & 1.15 & 0.92 & 1.44 \\
\hline & \multicolumn{3}{|c|}{ ( $p$ for trend) 0.23} & \multicolumn{3}{|c|}{ ( $p$ for trend) 0.38} & \multicolumn{3}{|c|}{ ( $p$ for trend) 0.22} & \multicolumn{3}{|c|}{ ( $p$ for trend) $\mathbf{0 . 0 0 2}$} & \multicolumn{3}{|c|}{ ( $p$ for trend) 0.78} & \multicolumn{3}{|c|}{ ( $p$ for trend) 0.92} & \multicolumn{3}{|c|}{ ( $p$ for trend) 0.86} \\
\hline
\end{tabular}

Frequency of changing diaper (ref. not at all)

\begin{tabular}{|c|c|c|c|c|c|c|c|c|c|c|c|c|c|c|c|c|c|c|c|c|c|}
\hline rarely & 0.99 & 0.88 & 1.13 & 0.95 & 0.78 & 1.15 & 0.91 & 0.76 & 1.11 & 0.87 & 0.75 & 1.01 & 1.06 & 0.91 & 1.24 & 1.12 & 0.84 & 1.50 & 1.05 & 0.89 & 1.24 \\
\hline mes & 0.93 & 0.83 & 1.05 & 0.90 & 0.76 & 1.08 & 0.95 & 0.80 & 1.14 & 0.85 & 0.74 & 0.98 & 0.97 & 0.84 & 1.13 & 1.00 & 0.76 & 1.32 & 0.99 & 0.85 & 6 \\
\hline lays & 0.97 & 0.81 & 1.15 & 0.88 & 0.68 & 1.14 & 0.97 & 0.75 & 1.25 & 0.74 & 0.60 & 0.92 & 1.13 & 0.92 & 1.40 & 1.08 & 0.71 & 1.64 & 1.00 & 80 & \\
\hline
\end{tabular}

( $p$ for trend) $0.21 \quad$ ( $p$ for trend) 0.22 ( $p$ for trend) 0.92 ( $p$ for trend) $0.01 \quad$ ( $p$ for trend) $0.97 \quad$ ( $p$ for trend) $0.83 \quad$ ( $p$ for trend) 0.73

Frequency of bathing (ref. not at all)

\begin{tabular}{|c|c|c|c|c|c|c|c|c|c|c|c|c|c|c|c|c|c|c|c|c|c|}
\hline rarely & 0.95 & 0.79 & 1.15 & 1.11 & 0.84 & 1.48 & 1.03 & 0.78 & 1.36 & 0.91 & 0.73 & 1.15 & 0.95 & 0.76 & 1.19 & 1.09 & 0.72 & 1.63 & 0.84 & 0.66 & 1.08 \\
\hline sometimes & 0.91 & 0.77 & 1.07 & 0.86 & 0.67 & 1.10 & 0.87 & 0.68 & 1.11 & 0.92 & 0.76 & 1.12 & 0.93 & 0.77 & 1.13 & 0.82 & 0.57 & 1.17 & 0.82 & 0.66 & 1.01 \\
\hline 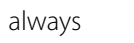 & 0.88 & 0.74 & 1.05 & 0.82 & 0.63 & 1.07 & 0.88 & 0.69 & 1.15 & 0.92 & 0.75 & 1.14 & 0.92 & 0.75 & 1.14 & 0.76 & 0.52 & 1.12 & 0.93 & 0.75 & 6 \\
\hline & $(k$ & & 13 & $(p f$ & & 0.01 & $(p)$ & & 0.19 & $(p$ & & 0.67 & $(p f$ & & 0.46 & & & & & & \\
\hline
\end{tabular}

Frequency of putting the child to sleep (ref. not at all)

$\begin{array}{llllllllllllllllllllll}\text { rarely } & 1.02 & 0.92 & 1.13 & 1.01 & 0.86 & 1.19 & 0.93 & 0.80 & 1.08 & 0.97 & 0.86 & 1.10 & 1.09 & 0.97 & 1.24 & 1.02 & 0.80 & 1.29 & 0.99 & 0.86 & 1.13 \\ \text { sometimes } & 1.03 & 0.93 & 1.14 & \mathbf{1 . 2 0} & \mathbf{1 . 0 3} & \mathbf{1 . 4 0} & 0.87 & 0.75 & 1.02 & 0.93 & 0.82 & 1.05 & \mathbf{1 . 1 4} & \mathbf{1 . 0 1} & \mathbf{1 . 2 9} & 1.05 & 0.83 & 1.33 & 0.95 & 0.83 & 1.09 \\ \text { always } & 0.96 & 0.83 & 1.11 & 1.04 & 0.83 & 1.30 & 0.88 & 0.71 & 1.10 & 0.90 & 0.76 & 1.08 & 1.07 & 0.90 & 1.28 & 0.86 & 0.60 & 1.24 & 0.89 & 0.73 & 1.08 \\ & & (p \text { for trend) } & 0.94 & (p \text { for trend) } & 0.08 & (p \text { for trend) } 0.11 & (p \text { for trend) } 0.16 & \text { ( } p \text { for trend) } 0.14 & (p \text { for trend) } 0.78 & (p \text { for trend) } 0.21\end{array}$

Frequency of playing with the child at home (ref. not at all)

\begin{tabular}{|c|c|c|c|c|c|c|c|c|c|c|c|c|c|c|c|c|c|c|c|c|c|}
\hline rarely & 0.88 & 0.54 & 1.43 & 0.95 & 0.48 & 1.89 & 0.86 & 0.44 & 1.65 & 0.63 & 0.38 & 1.06 & 1.27 & 0.70 & 2.32 & 0.89 & 0.36 & 2.23 & 0.97 & 0.52 & 1.81 \\
\hline sometimes & 0.86 & 0.54 & 1.35 & 0.75 & 0.39 & 1.44 & 0.72 & 0.39 & 1.34 & 0.54 & 0.33 & 0.88 & 1.10 & 0.62 & 1.95 & 0.66 & 0.28 & 1.56 & 0.97 & 0.54 & 1.75 \\
\hline \multirow[t]{2}{*}{ always } & 0.75 & 0.47 & 1.20 & 0.64 & 0.33 & 1.25 & 0.67 & 0.36 & 1.25 & 0.48 & 0.29 & 0.78 & 0.96 & 0.54 & 1.70 & 0.56 & 0.23 & 1.36 & 0.83 & 0.46 & 1.50 \\
\hline & \multicolumn{3}{|c|}{$\begin{array}{l}\text { ( } p \text { for trend }) \\
0.002\end{array}$} & \multicolumn{3}{|c|}{$\begin{array}{l}\text { ( } p \text { for trend) } \\
0.001\end{array}$} & \multicolumn{3}{|c|}{$\begin{array}{l}\text { ( } p \text { for trend) } \\
0.05\end{array}$} & \multicolumn{3}{|c|}{$\begin{array}{l}(p \text { for trend }) \\
<0.001\end{array}$} & \multicolumn{3}{|c|}{$\begin{array}{l}\text { ( } p \text { for trend) } \\
\mathbf{0 . 0 0 3}\end{array}$} & \multicolumn{3}{|c|}{$\begin{array}{l}\text { ( } p \text { for trend) } \\
0.02\end{array}$} & \multicolumn{2}{|c|}{$\begin{array}{l}(p \text { for trend) } \\
0.01\end{array}$} & \\
\hline
\end{tabular}

Frequency of taking the child outside (ref. not at all)

\begin{tabular}{|c|c|c|c|c|c|c|c|c|c|c|c|c|c|c|c|c|c|c|c|c|c|}
\hline rarely & 0.78 & 0.63 & 0.97 & 0.85 & 0.62 & 1.17 & 0.99 & 0.71 & 1.36 & 0.85 & 0.66 & 1.09 & 0.90 & 0.70 & 1.15 & 0.76 & 0.49 & 1.17 & 0.96 & 0.73 & 1.25 \\
\hline sometimes & 0.75 & 0.62 & 0.92 & 0.82 & 0.61 & 1.11 & 0.95 & 0.70 & 1.29 & 0.89 & 0.70 & 1.13 & .83 & 0.65 & 1.05 & 0.69 & 0.46 & 1.04 & 0.80 & 0.62 & 1.03 \\
\hline & 0.71 & 0.57 & 0.89 & 0.79 & 0.57 & 1.11 & 0.90 & 0.64 & 1.26 & 0.82 & 0.63 & 1.07 & 0.77 & 0.59 & 1.00 & 0.73 & 0.46 & 1.16 & 0.67 & 0.51 & 0 \\
\hline & $(p$ & & 0.01 & $(p \mathrm{fc}$ & reng & 0.24 & $(p f$ & & 038 & ( & & 0.39 & & & & & & & & & \\
\hline
\end{tabular}

${ }^{2}$ Adjusted covariates (number of siblings, living with grandparent(s), paternal and maternal age at child birth, paternal and maternal education, annual household income, maternal childcare hours on weekdays or weekends at 18 months old, and the total scores of maternal involvement in caregiving, gestational age, multiple birth, child's history of hospital admission or visits for congenital diseases, child's temperament), and parental spending hours with children.

${ }^{\mathrm{b}}$ Bold values denote statistical significance at the $p<0.05$

$O R$ Odds ratio; $\mathrm{Cl}$ Confidence interval

behavior. According to previous studies, mothers' evaluations of paternal childcare are susceptible to influence by marital satisfaction and maternal emotional wellbeing [41, 42]. Other objective measures of paternal childcare should be used in future studies. Second, the outcome in this study, that is, behavioral problems in 5.5-year-old children, were also self-reported by their mothers. Mothers may be one of the primary caregivers for children in most cases; however, they may not be able to fully observe their child's behavior in situations other than at home. Furthermore, the measurements for child problem behavior in this study are not sufficiently validated although they are used in previous studies [22, 23]. However, the behavioral questions in this study are similar to those on the Strengths and Difficulties Questionnaire (SDQ), which is a validated child behavioral 
screening instrument. The SDQ consists of 25 questions with five subscales: emotional problems, conduct problems, hyperactivity/inattention, peer problems, and prosocial behavior [43, 44]. For example, "unable to focus on a specific task" in our questionnaire is similar to "Restless, overactive, cannot stay still for long" on SDQ, and "behave in a group situation" in our questionnaire is similar to "Shares readily with other children (treats, toys, and pencils, etc.)" on SDQ. Third, our results could still be biased by residual confounding that we could not measure in this survey, such as marital relationships or paternal mental health. Data about the father's health or relationships with their partners are scarce, so their potential effects on paternal childcare and child development are not widely recognized [45]. Researchers and practitioners would need to take these family factors into account when considering the interactions between fathers and children.

\section{Conclusions}

Despite these limitations, the present study suggests that paternal childcare in the toddlerhood could prevent subsequent behavioral problems in children based on a national prospective study in Japan. Our study also showed that several specific caregiving behaviors by fathers, such as playing with their children at home or taking them outside, may play an important role in appropriate behavioral development in early childhood, which depends on the child's sex. Promoting paternal childcare support would augment the quantity and quality of paternal caregiving, which in turn could have a beneficial effect on child behavioral development. The policies that support child-rearing fathers, including the promotion of work environments that facilitate paid parental leave, restriction of overtime work, and incentives for remote or flex-time work, could be linked to the prevention of behavioral problems in children. Further studies using more detailed data on paternal childcare are required to elucidate the mechanisms by which fathers' involvement in childcare could have a protective effect on early childhood behavior.

\section{Abbreviations}

OR: Odds ratio; Cl: Confidence interval; SD: Standard deviation; SE: Standard error

\section{Supplementary Information}

The online version contains supplementary material available at https://doi. org/10.1186/s12887-021-02838-2.

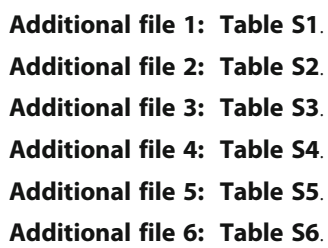

\section{Acknowledgements}

Not applicable.

\section{Authors' contributions}

MO conceptualized and designed the study, coordinated the study, analyzed data, drafted the initial manuscript, and reviewed and revised the manuscript. TF conceptualized and designed the study, coordinated and supervised the study, reviewed and revised the manuscript. All authors approved the final manuscript as submitted and agree to be accountable for all aspects of the work.

\section{Funding}

Grants-in-Aid for Scientific Research from the Japan Society for the Promotion of Science (JSPS KAKENHI Grant Number 16H03276).

\section{Availability of data and materials}

The data that support the findings of this study are available from the Ministry of Health, Labor, and Welfare in Japan (MHLW) but restrictions apply to the availability of these data, which were used under license for the current study, and so are not publicly available. The point of contact in MHLW from the data can be requested: Examination and Analysis Office, Director-General for Statistics and Information Policy. Central Joint Government Building No.5, 1-2-2 Kasumigaseki, Chiyoda-ku, Tokyo. 100-8916. Tel: + 81-3-5253-1111 (ext. 7391), Email: mokutekigai@mhlw.go.jp

\section{Declarations}

Ethics approval and consent to participate

All procedures were conducted in accordance with the Declaration of Helsinki and Ethical Guidelines for Medical and Health Research Involving Human Subjects. Approval from the ethics committee of the Tokyo Medical and Dental University was waived because the data were anonymous and available from the Ministry of Health, Labour, and Welfare in Japan upon request. Questionnaire responses from participants were considered as informed consent to participate in the study.

\section{Consent for publication}

Not applicable.

\section{Competing interests}

The authors declare that they have no competing interests.

Received: 1 April 2021 Accepted: 12 August 2021

Published online: 10 September 2021

\section{References}

1. Lamb ME. The role of the father in child development. New York: John Wiley \& Sons; 2004.

2. Yogman MW, Kindlon D, Earls F. Father involvement and cognitivebehavioral outcomes of preterm infants. J Am Acad Child Adolesc Psychiatry. 1995;34(1):58-66. https://doi.org/10.1097/00004583-19950100000015.

3. Tamis-LeMonda CS, Shannon JD, Cabrera NJ, Lamb ME. Fathers and mothers at play with their 2- and 3-year-olds: contributions to language and cognitive development. Child Dev. 2004;75(6):1806-20. https://doi.org/1 0.1111/j.1467-8624.2004.00818.x.

4. Black MM, Dubowitz H, Starr RH. African American fathers in low income, urban families: development, behavior, and home environment of their three-year-old children. Child Dev. 1999;70(4):967-78. https://doi.org/1 0.1111/1467-8624.00070.

5. Abate KH, Belachew T. Women's autonomy and men's involvement in child care and feeding as predictors of infant and young child anthropometric indices in coffee farming households of Jimma zone, South West of Ethiopia. PLoS One. 2017;12(3):e0172885. https://doi.org/10.1371/journal.pone.0172885.

6. Lindsey EW, Cremeens PR, Caldera YM. Mother-child and father-child mutuality in two contexts: consequences for young children's peer relationships. Infant Child Dev. 2010;19(2):142-60.

7. King V. Nonresident father involvement and child well-being - can dads make a difference. J Fam Issues. 1994;15(1):78-96. https://doi.org/10.1177/01 9251394015001004. 
8. Flouri E, Buchanan A. Early father's and mother's involvement and child's later educational outcomes. Br J Educ Psychol. 2004;74(2):141-53. https:// doi.org/10.1348/000709904773839806.

9. Fujiwara T, Okuyama M, Takahashi K. Paternal involvement in childcare and unintentional injury of young children: a population-based cohort study in Japan. Int J Epidemiol. 2010;39(2):588-97. https://doi.org/10.1093/ije/dyp340.

10. Sarkadi A, Kristiansson R, Oberklaid F, Bremberg S. Fathers' involvement and children's developmental outcomes: a systematic review of longitudinal studies. Acta Paediatr. 2008;97(2):153-8. https://doi.org/10.1111/j.1651-2227.2 007.00572.x

11. Flouri E, Malmberg L-E. Father involvement, family poverty and adversity, and young children's behaviour in intact two-parent families. Longit Life Course Stud. 2012;3(2):254-67.

12. Kroll ME, Carson C, Redshaw M, Quigley MA. Early father involvement and subsequent child behaviour at ages 3,5 and 7 years: prospective analysis of the UK millennium cohort study. PLoS One. 2016;11(9):e0162339. https://doi. org/10.1371/journal.pone.0162339.

13. Flouri E, Midouhas E, Narayanan MK. The relationship between father involvement and child problem behaviour in intact families: a 7-year crosslagged study. J Abnorm Child Psychol. 2016;44(5):1011-21. https://doi.org/1 0.1007/s10802-015-0077-9.

14. Fagan J, Day R, Lamb ME, Cabrera NJ. Should researchers conceptualize differently the dimensions of parenting for fathers and mothers? J Fam Theory Rev. 2014;6(4):390-405.

15. McMunn A, Martin P, Kelly Y, Sacker A. Fathers' involvement: correlates and consequences for child socioemotional behavior in the United Kingdom. J Fam Issues. 2017;38(8):1109-31. https://doi.org/10.1177/0192513X15622415.

16. Lengua LJ. Growth in temperament and parenting as predictors of adjustment during children's transition to adolescence. Dev Psychol. 2006; 42(5):819-32. https://doi.org/10.1037/0012-1649.42.5.819.

17. Chang LR, Chiu YN, Wu YY, Gau SSF. Father's parenting and father-child relationship among children and adolescents with attention-deficit/ hyperactivity disorder. Compr Psychiatry. 2013;54(2):128-40. https://doi.org/1 0.1016/j.comppsych.2012.07.008.

18. Shwalb DW, Shwalb BJ. Fatherhood in Brazil, Bangladesh, Russia, Japan, and Australia. Online Read Psychol Culture. 2014;6(3):4.

19. Nishioka H. Men's domestic role and the gender system: determinants of husband's household labor in Japan ("Daiikkai zenkokukateidoukouchousa" data riyouniyorujisshotekikenkyu). Jinko Mondai Kenkyu (Journal of Population Problems). 1998:54(3):56-71.

20. Nakazawa J, Shwalb DW. Fathering in Japan: entering an era of involvement with children. In: Shwalb DW, Shwalb BJ, Lamb ME, editors. Fathers in cultural context. New York: Routledge; 2013. p. 42-66.

21. Sato R, Fujiwara T, Kino S, Kawachi I. The association between father involvement in caregiving and early childhood overweight or obesity. Pediatr Obes. 2020;15(9):e12652. https://doi.org/10.1111/ijpo.12652.

22. Yorifuji T, Kubo T, Yamakawa M, Kato T, Inoue S, Tokinobu A, et al. Breastfeeding and behavioral development: a nationwide longitudinal survey in Japan. J Pediatr. 2014;164(5):1019-25. https://doi.org/10.1016/j. jpeds.2014.01.012.

23. Okuzono S, Fujiwara T, Kato T, Kawachi I. Spanking and subsequent behavioral problems in toddlers: a propensity score-matched, prospective study in Japan. Child Abuse Negl. 2017;69:62-71. https://doi.org/10.1016/j. chiabu.2017.04.002

24. Cabrera N, Fitzgerald HE, Bradley RH, Roggman L. Modeling the dynamics of paternal influences on children over the life course. Appl Dev Sci. 2007; 11(4):185-9. https://doi.org/10.1080/10888690701762027.

25. Brown GL, McBride BA, Bost KK, Shin NN. Parental involvement, child temperament, and parents' work hours: differential relations for mothers and fathers. J Appl Dev Psychol. 2011;32(6):313-22. https://doi.org/10.1016/ j.appdev.2011.08.004

26. Leonard LG, Denton J. Preparation for parenting multiple birth children. Early Hum Dev. 2006;82(6):371-8. https://doi.org/10.1016/j.earlhumdev.2006. 03.009.

27. Hines M. Sex-related variation in human behavior and the brain. Trends Cogn Sci. 2010;14(10):448-56. https://doi.org/10.1016/j.tics.2010.07.005.

28. Baxter J, Smart D. Fathering in Australia among couple families with young children. Australian Department of Families, Housing, Community Services and Indigenous Affairs, Occasional Paper, vol. 37; 2011.

29. Amato PR, Rivera F. Paternal involvement and children's behavior problems. J Marriage Fam. 1999;61(2):375-84. https://doi.org/10.2307/353755.
30. Russell G, Hwang CP. The impact of workplace practices on fathe involvement. In: Lamb M, editor. The role of the father in child development, vol. 4. Hoboken: J Fam Issues; 2004. p. 476-503.

31. Ishii-Kuntz M. Work environment and Japanese Fathers' involvement in child care. J Fam Issues. 2013;34(2):252-71.

32. Lewis SN, West AF, Stein A, Malmberg LE, Bethell K, Barnes J, et al. A comparison of father-infant interaction between primary and non-primary care giving fathers. Child Care Health Dev. 2009;35(2):199-207. https://doi. org/10.1111/j.1365-2214.2008.00913.x.

33. Talge NM, Neal C, Glover V. Early stress trapsnfaneocaamh. Antenatal maternal stress and long-term effects on child neurodevelopment: how and why? J Child Psychol Psychiatry. 2007;48(3-4):245-61. https://doi.org/1 0.1111/j.1469-7610.2006.01714.x

34. Crnic KA, Gaze C, Hoffman C. Cumulative parenting stress across the preschool period: relations to maternal parenting and child behaviour at age 5. Infant Child Dev. 2005;14(2):117-32. https://doi.org/10.1002/icd.384

35. Paquette $D$. Theorizing the father-child relationship: mechanisms and developmental outcomes. Hum Dev. 2004;47(4):193-219. https://doi.org/1 $0.1159 / 000078723$

36. Baker M, Milligan K. Boy-girl differences in parental time investments: evidence from three countries. J Hum Cap. 2016;10(4):399-441. https://doi. org/10.1086/688899.

37. Harewood T, Vallotton CD, Brophy-Herb H. More than just the breadwinner: the effects of fathers' parenting stress on children's language and cognitive development. Infant Child Dev. 2017;26(2):19.

38. Emmott EH, Mace R. Why the son-bias in caregiving? Testing sex-differences in the associations between paternal caregiving and child outcomes in England. J Fam Issues. 2020;42(6):1354-83.

39. White Paper on Gender Equality. In: office GEBC, editor. Tokyo: Cabinet Office; 2019. p. 2019.

40. JILPT. Databook of international labour statistics 2018. Tokyo: The Japan Institute for Labour Policy and Training; 2018.

41. Fagan J, Lee $Y$. Perceptions and satisfaction with father onvolvement and adolescent mothers' postpartum depressive symptoms. J Youth Adolesc. 2010;39(9):1109-21. https://doi.org/10.1007/s10964-009-9444-6.

42. Kwok S, Cheng L, Chow BWY, Ling CCY. The spillover effect of parenting on marital satisfaction among chinese mothers. J Child Fam Stud. 2015;24(3): 772-83. https://doi.org/10.1007/s10826-013-9888-x.

43. Goodman R, Meltzer H, Bailey V. The strengths and difficulties questionnaire: a pilot study on the validity of the self-report version. Eur Child Adolesc Psychiatry. 1998;7(3):125-30. https://doi.org/10.1007/s007870050057.

44. Matsuishi T, Nagano M, Araki Y, Tanaka Y, Iwasaki M, Yamashita Y, et al. Scale properties of the Japanese version of the strengths and difficulties questionnaire (SDQ): a study of infant and school children in community samples. Brain and Development. 2008;30(6):410-5. https://doi.org/10.1016/j. braindev.2007.12.003.

45. Musser AK, Ahmed AH, Foli K, Coddington JA. Paternal postpartum depression: what health care providers should know. J Pediatr Health Care. 2013;27(6):479-85. https://doi.org/10.1016/j.pedhc.2012.10.001.

\section{Publisher's Note}

Springer Nature remains neutral with regard to jurisdictional claims in published maps and institutional affiliations.

Ready to submit your research? Choose BMC and benefit from:

- fast, convenient online submission

- thorough peer review by experienced researchers in your field

- rapid publication on acceptance

- support for research data, including large and complex data types

- gold Open Access which fosters wider collaboration and increased citations

- maximum visibility for your research: over $100 \mathrm{M}$ website views per year

At BMC, research is always in progress.

Learn more biomedcentral.com/submissions 